\title{
Sustentabilidad, patrimonio cultural, turismo y participación. Lineamientos para la gestión de un pueblo indígena en Argentina
}

\author{
Sustainability, cultural heritage, tourism and participation. Guidelines \\ for the management of an indigenous people in Argentina
}

\author{
María Vanesa Giacomasso* \\ Universidad Nacional del Centro de la Provincia de Buenos Aires (FACSO-UNICEN), Argentina \\ Laura Zulaica \\ Universidad Nacional de Mar del Plata (FAUD-UNMDP), Argentina
}

\section{RESUMEN}

La sustentabilidad en la provincia de San Luis (Argentina) con eje en la salvaguardia del patrimonio cultural ha sido parte de los objetivos de la agenda política desde comienzos del siglo XXI. En este marco jugaron un papel central las poblaciones indígenas, para las cuales se efectuaron programas de restitución de tierras y construcción de viviendas con el fin de promover su reactivación cultural. En este contexto, por medio de un estudio cualitativo, basado en la realización de entrevistas, observaciones participantes y relevamiento de fuentes documentales, se analiza el caso de construcción de Pueblo Ranquel, un asentamiento de familias indígenas rankülches, inaugurado en 2009 cuyo surgimiento, orientado a la promoción turística, fue promovido principalmente desde sectores gubernamentales. El objetivo final de este trabajo es presentar una serie de lineamientos que emergen del análisis del caso y de una reflexión teórico-metodológica sobre la importancia de la participación de los distintos actores involucrados en las políticas culturales.

Palabras clave: sustentabilidad, patrimonio, turismo, gestión participativa, pueblos indígenas.

\begin{abstract}
Sustainability in the province of San Luis (Argentina), centered on the safeguarding of cultural heritage, has been part of the objectives of the political agenda since the beginning of the 21 st century. In this framework, the indigenous populations played a central role, for whom land restitution and housing construction programs were carried out in order to promote their cultural reactivation. In this context, through a qualitative study based on conducting interviews, participant observations and a survey of documentary sources, the case of the
\end{abstract}


construction of "Pueblo Ranquel" is analyzed, a settlement of Rankülche indigenous families inaugurated in 2009, whose emergence, aimed at promoting tourism, was promoted mainly by government sectors. The final objective of this work is to present a series of guidelines that emerge from the analysis of the case and from a theoretical-methodological reflection on the importance of the participation of the different actors involved in cultural policies.

Keywords: sustainability, heritage, tourism, participative management, indigenous peoples.

\section{Introducción}

En los últimos años, específicamente a mediados de la década del 2000, en la provincia argentina de San Luis se han impulsado acciones vinculadas con la sustentabilidad regional, a partir del compromiso que algunas ciudades provinciales asumieron con la Agenda 2030 de Desarrollo Sostenible. Esta agenda aprobada en 2015 por 193 Estados Miembros de la Organización de las Naciones Unidas (ONU), entre ellos Argentina, establece un plan de acción ${ }^{1}$ que conjuga las dimensiones económica, sociocultural y ambiental para construir sociedades a favor de las personas, el planeta y la prosperidad, y que ha impactado en las gestiones llevadas a cabo por varias regiones del país.

Recientemente, en junio de 2020, la provincia de San Luis aprobó un proyecto que impulsa al gobierno provincial a firmar un convenio con el Consejo Nacional de Coordinación de Políticas Sociales de la Presidencia de la Nación para adherir a los Objetivos de Desarrollo Sostenible (ODS). No obstante esta iniciativa, San Luis contaba con proyectos en esa línea de compromiso con la Agenda 2030 desde una perspectiva ambiental como el llamado Tratado de Paz entre Progreso y Medio Ambiente - Estrategia 2010-2020", el Programa de Industria, Agroindustria y Minero que enfatiza en el desarrollo de una producción sustentable y un ambiente saludable; así como proyectos relacionados con la revalorización de la biodiversidad, la naturaleza y la cultura de San Luis $^{2}$ a través de la formación de circuitos turísticos, naturales y culturales. Asimismo, en la última década se destaca el interés provincial por fortalecer la identidad y el vínculo de los pobladores con el territorio, lo cual ha sido visibilizado a través del concepto de puntanidad ${ }^{3}$, basado en la idea de distinguir y valorar los saberes tradicionales puntanos, los hitos, la fauna, la gastronomía, las personas representativas de la región, la historia

1. El plan incluye 17 objetivos dentro de los cuales el punto 11 se refiere a las ciudades y comunidades sostenibles. Ver https:// es.unesco.org/sdgs.

2. Estos proyectos forman parte de la planificación de políticas del Ministerio de Turismo de la provincia y cuentan con el programa de "Apoyo tecnológico al sector Turismo" (ASETUR) implementado por el Ministerio de Ciencia y Tecnología.

3. San Luis fue conocida frecuentemente con el nombre de La Punta proveniente de la sierra de San Luis conocida como Punta de los Venados -que formó parte de los límites que comenzaban a delimitarse en su fundación en 1594- y cuyo nombre deriva de la gran cantidad de Venados de las Pampas que había en el territorio. Cabe destacar que el escudo provincial refleja sobre un fondo montañoso dos venados enfrentados. En este sentido, la "puntanidad", alude a la identificación con aspectos que se consideran característicos y distintivos de la provincia. 
y la prehistoria, la filosofía ancestral y los modos de expresión, entre otras cosas que dan sentido de pertenencia a todos los habitantes de la provincia.

En esa línea, cabe señalar las políticas de reivindicación cultural hacia los pueblos indígenas de la zona -a partir de concretas medidas de restitución de tierras y construcción de viviendas llevadas a cabo desde el 2007- como forma de revalorizar y salvaguardar ${ }^{4}$ el patrimonio y la cultura de estos grupos considerados raíz de lo sanluiseño (Chocobare, 2016). Con relación a ello, se destaca además, el objetivo de promoción turística de estos espacios a favor de hacer visibles a los grupos étnicos de San Luis y como una oportunidad para el desarrollo y sostenibilidad de los mismos.

En este marco, el presente trabajo responde a dos objetivos principales: (1) analizar la creación de Pueblo Ranquel -un asentamiento de familias originarias rankülches promovido por el gobierno provincial- poniendo especial atención a los procesos y gestiones que se dan en él y a los modos de sustentabilidad y desarrollo sociocultural impulsado desde su creación hasta la actualidad; (2) hacer una reflexión crítica sobre las gestiones culturales, sus metodologías de acción e impacto social, en tanto obstaculizadoras o favorecedoras de procesos de sustentabilidad regional; partiendo de una investigación más amplia (Giacomasso, 2016).

Por lo tanto, se hace referencia al concepto de sustentabilidad, su vínculo con lo cultural y, por ende, con el patrimonio cultural, incorporando su relación con el turismo; luego, se contextualiza el caso de Pueblo Ranquel como otra política más de San Luis, orientada a recuperar una identidad cultural inclusiva y, además, se describen los proyectos diseñados para la sostenibilidad de sus habitantes, centrados en la programación de un turismo étnico. También, se discute sobre las políticas de gestión cultural y se proponen lineamientos que incluyen estrategias para la puesta en marcha de dinámicas participativas y sustentables para las comunidades.

Para este artículo, se recuperó la investigación desarrollada en Pueblo Ranquel por Giacomasso (2016), basada en un trabajo de campo etnográfico a través de la realización de entrevistas abiertas y en profundidad, observación participante y registro de relatos de los actores involucrados (Guber, 2011; Van Maanen, 1995). Su giro analítico desde el punto de vista de la sustentabilidad requirió, asimismo, del relevamiento y análisis de legislaciones y documentos vinculados con las políticas de gestión cultural y, a su vez, del relevamiento de fuentes periodísticas (prensa gráfica) referidas al desarrollo y turismo provincial.

4. Se entiende por salvaguardia las medidas de identificación, documentación, investigación, preservación, protección, promoción, valorización, transmisión y revitalización del patrimonio en sus distintos aspectos (UNESCO 2014a). 


\section{Consideraciones teóricas}

\section{El desarrollo sustentable desde su dimensión sociocultural}

Las preocupaciones por la problemática ambiental ingresan a la agenda internacional en la década de 1970. Sin embargo, no fue hasta la década de 1980 que se gesta la noción de desarrollo sustentable como alternativa al enfoque tradicional de desarrollo económico y social dominante, sobre la base de la idea de un progreso material infinito e ilimitado (Gallopin, 2003). En este sentido, si bien en sus orígenes el concepto de sustentable estuvo ligado fundamentalmente con la idea de crecimiento económico, en los años 90 se fortalece la interpretación que reconoce la necesaria articulación entre la capacidad de sustentación del ambiente y del territorio, y una adecuada calidad de vida para la población abarcando así distintas dimensiones (Fernández et al., 1999). De este modo, la sustentabilidad abarca distintas dimensiones y la noción de desarrollo actualmente se concibe como integral de las personas, por lo que el crecimiento económico es valorado en tanto es capaz de satisfacer las necesidades humanas, así como del ambiente natural (Iglesias y Martínez, 2007).

A partir de esta perspectiva el desarrollo sustentable se entiende como la posibilidad de que todas las personas amplíen y aprovechen plenamente su capacidad en todas las esferas, ya sea económica, natural, social, cultural y política, a favor de la promoción del empleo productivo y la reducción de la pobreza; la integración social y la regeneración del ambiente (Iglesias y Martínez, 2007). Si bien el concepto de sustentabilidad es ampliamente discutido en la literatura por su versatilidad y ambigüedad, se han realizado esfuerzos por sintetizar las dimensiones y características a considerar en el desarrollo sustentable. Así por ejemplo, Guimarães (2003), enuncia y explica distintas dimensiones contenidas en el concepto de sustentabilidad que pueden sintetizarse de la siguiente forma: (a) una dimensión ecológica, que implica preservar la integridad de los procesos naturales que garantizan los flujos de energía y materiales en la biósfera y que, a la vez, preserva la biodiversidad en su sentido más amplio; (b) una dimensión social y cultural, que promueve el mantenimiento del sistema de valores, prácticas y símbolos de identidad, la igualdad y el bienestar humano; (c) una dimensión económica, tendiente a la gestión adecuada de los bienes congruente con las metas de la sustentabilidad ecológica; y (d) una dimensión política, que privilegia la complementariedad entre los mecanismos de mercado y la regulación pública promovida como política de Estado.

En este último punto, Achkar (2005) plantea la importancia de la participación directa de las personas en la toma de decisiones, en la definición de los futuros colectivos y en la gestión de los bienes públicos. Este cambio trascendental en la concepción sobre el desarrollo sustentable aparece ligado al reconocimiento del mismo como un derecho humano, tanto en la Declaración Universal de Derechos Humanos de 1948, como en el Pacto de Derechos Económicos, Sociales y Culturales de 1966 y la Declaración sobre el Derecho al Desarrollo de la ONU de 1986. En estos acuerdos se reconoce el derecho a gozar de un ambiente sano y equilibrado, a la paz y la libre determinación de los pueblos para su desarrollo y al patrimonio común de la humanidad. Del mismo modo, el derecho a gozar de un ambiente sano y equilibrado, así como el deber de preservarlo se plasma en 
el artículo 41 de la Constitución Nacional en la reforma de 1994 y en el artículo 47 de la Constitución de la provincia de San Luis, incorporado en 1987.

\section{El patrimonio cultural como eje para el desarrollo}

El patrimonio cultural no es ajeno a las dimensiones integradoras del desarrollo humano sustentable. Por el contrario, se lo considera un eje central y de relevancia para la cultura y el desarrollo, en tanto constituye "el capital cultural" de las sociedades contemporáneas y su enriquecimiento ayuda a mantener la cohesión social y territorial, a la par que a promover la paz y el desarrollo social, ambiental y económico sostenible (UNESCO, 2014a, p. 132). El patrimonio encierra no solo el potencial de generar el acceso a la diversidad cultural y su disfrute, sino también motoriza la economía de muchas regiones a partir de su promoción turística sostenida en los principios de la sustentabilidad.

Cabe destacar que el patrimonio cultural se entiende como el conjunto de bienes, tanto tangibles como intangibles, que se heredan del pasado y se construyen en el presente, asociados con una determinada identidad (Bonfil, 2004; García, 1999; Prats, 2007; Rosas, 2005); y que requiere ser salvaguardado a través de las generaciones. Comparte con los recursos naturales su carácter de no renovable y, por ende, necesita de políticas y modelos de desarrollo sustentable que lo preserven (UNESCO, 2014a). En este sentido, se reconoce que el patrimonio existe como tal en la medida en que es valorado y activado por los grupos que realizan sobre él determinadas actuaciones para preservarlo. Sobre esta cuestión, Prats (2005) sostiene que dichas activaciones dependen, la mayoría de las veces, de los poderes políticos, los cuales a su vez cuentan con el apoyo de los poderes económicos (que garantizan la disponibilidad de recursos) y académicos (que buscan certificar el rigor científico de las activaciones). Sin embargo, el proceso no es tan simple, sino que requiere negociar con otros poderes fácticos y con la propia sociedad civil respecto de aquellos elementos valorados y representativos de los grupos, como fruto normalmente de procesos identitarios. Ello dependerá de los valores que se pongan en juego en cada activación, que pueden priorizar aspectos políticos y económicos, hasta educativos, estéticos o simbólico-identitarios.

Dentro de este marco no puede eludirse otra dimensión que gana cada vez más fuerza, en las sociedades actuales, y que se relaciona con las activaciones ligadas al mercado turístico, las cuales muchas veces pasan a evaluarse en términos de consumo y de su eficacia en la contribución al desarrollo o consolidación del mercado lúdico-turístico-cultural. En algunos casos suele generarse la "espectacularización” en torno a los repertorios del patrimonio y la trivialización, superficialidad y reducción de las múltiples significaciones y valoraciones identitarias de los diversos grupos que las portan (Prats, 2005).

A pesar de los impactos positivos que el turismo puede generar sobre el patrimonio, en numerosas ocasiones se advierte que los itinerarios turístico-culturales pueden descontextualizar el patrimonio, desarticular los territorios donde se emplazan y construir imágenes territoriales que no siempre se corresponden con las realidades culturales de las sociedades que intentan representar. Incluso, en algunas situaciones, en lugar de 
actuar en pos de la salvaguarda del patrimonio generan o intensifican procesos de destrucción. En la mayoría de los casos esto es un reflejo de políticas públicas exclusivas que no incluyen a los agentes culturales en el proceso de planificación turística.

En este sentido, evaluar la sustentabilidad patrimonial y turística desde una dimensión sociocultural y en relación con las comunidades resulta una cuestión clave. Esta perspectiva, de acuerdo a García y Priotto (2008), permite fortalecer el sistema de valores, prácticas y símbolos de identidad para la reproducción del tejido social y para garantizar la integración a lo largo del tiempo. Mientras tanto, Elizalde (2003) afirma que la dimensión sociocultural tiende a alcanzar la justicia social, es decir, lograr inclusión y equidad como condiciones necesarias de la existencia humana.

\section{El caso de San Luis}

\section{Patrimonio cultural, identidad y memoria sanluiseña}

El reconocimiento de las poblaciones indígenas en San Luis formó parte de un conjunto de acciones estatales relativamente recientes, enmarcadas en una idea de desarrollo social asociado a la revalorización de la cultura y el respeto por la diversidad. Previo a ello, hasta la primera década del siglo XXI, la historia, memoria e identidad de la provincia estuvo configurada en torno a la gesta criolla y heroica de próceres históricos, como hitos fundantes de la matriz identitaria de los sanluiseños. Ello no solo quedaba evidenciado en materialidades, a las que se les debía rendir homenaje, como por ejemplo, el monumento al coronel Juan Pascual Pringles (1912) en la plaza central de la ciudad de San Luis, o el más reciente monumento al Pueblo Puntano (1991), en el lugar donde había funcionado el campamento de reclutamiento militar Las Chacras ${ }^{5}$; sino también, a través de discursos legitimados que enfatizaban en los actos de "distinguidos" oficiales y soldados vinculados con el gobierno patrio y en los que los grupos indígenas quedaban invisibilizados.

El historiador Juan Gez (1916) ${ }^{6}$, a quien se le encarga en 1910 escribir la historia provincial, ya argumentaba en su obra que "el problema indígena" después de la Conquista del Desierto quedaba resuelto, al desaparecer ese "peligro para la civilización argentina" y al asegurarse en la provincia el "triunfo sobre el indio". Pero, a su vez, se ha analizado que en los discursos políticos institucionalizados -pronunciados por gobernadores provinciales desde la recuperación de la democracia hasta la primera mitad del presente siglo- los pueblos originarios estaban invisibilizados, silenciados y excluidos dentro de los significados, ideas y proyectos de construcción identitaria de lo puntano (Lobo, 2015).

A partir del año 2007, no obstante, comienza a emerger disruptivamente la visibilización y centralidad

5. Este campamento de reclutamiento, ubicado a $13 \mathrm{~km}$ de la actual ciudad de San Luis, estuvo destinado a preparar a granaderos a la orden del General José de San Martín.

6. Recién en 1996 pudo accederse a este material a partir de un trabajo de recopilación que el gobierno provincial hizo de su obra. 
de los pueblos indígenas, no solo desde lo discursivo como parte de narrativas que renuncian a la identidad regional de matriz criolla y católica; sino también desde acciones concretas que generaron la activación de estos "nuevos" sujetos indígenas y con ello, la visibilización de sus bienes culturales, prácticas, valoraciones y significados.

Al respecto, una serie de sanciones legales y declaraciones institucionales ponen en escena la presencia en la provincia de pueblos originarios que, hasta ese momento, se consideraban inexistentes. En el año 2007 se sanciona la ley provincial ( $\left.\mathrm{N}^{\mathrm{o}} \mathrm{V}-0600-07\right)$ que reconoce la "preexistencia étnica y cultural de todas las comunidades originarias del territorio" y establece "la restitución de las tierras que históricamente le han pertenecido" a los pueblos originarios que habiten la provincia (art. 2). En el año 2008, se aprueba la Ley provincial de Creación de Registro de las Comunidades Originarias y se crea el programa de gobierno Culturas Originarias, para coordinar las actividades relacionadas con los pueblos indígenas de la zona. Ese mismo año, se declara Año de las culturas originarias de San Luis y se proclama el 11 de octubre de 1492 como el día del último grito de libertad de los pueblos originarios, para ser incorporado a las conmemoraciones culturales y educativas a nivel provincial.

Sin dudas, estas políticas evidencian una activación estatal de los asuntos indígenas que pasan a ser reconocidos y valorados, no solo desde lo declaratorio y legal, sino también desde actos concretos como la restitución de 2500 ha de tierras al pueblo rankülche $e^{7}$ más tarde ampliadas a un total aproximado de 68000 ha- y la construcción de un pueblo para que habiten pobladores que se adscriban como tales y revitalicen su identidad, reconocida e incluida dentro de los valores de la puntanidad regional.

\section{Presentación de Pueblo Ranquel: descripción espacial, edilicia y ambiental}

Antes de comenzar con la caracterización del pueblo, es importante destacar que la información vertida sobre el caso forma parte de un exhaustivo trabajo metodológico que consistió en entrevistas con los distintos actores involucrados -hombres y mujeres habitantes del pueblo, funcionarios de gobierno, investigadores, etc.residencia en el lugar; observación participante y análisis de material documental, el cual incluyó noticias periodísticas del momento de creación de Pueblo Ranquel y de distintas actividades llevadas a cabo desde su inauguración, así como planes y programas de gobierno relacionados con gestiones culturales que incluyeron a los pueblos indígenas de la región.

Pueblo Ranquel, inaugurado en mayo del 2009, se ubica en una zona rural del centro-sur de la provincia de San Luis, a $27 \mathrm{~km}$ al norte de la localidad de Batavia -la más cercana- y a $200 \mathrm{~km}$ al sureste de la ciudad de San Luis, capital provincial (Figura 1). Esta área se encuentra retirada de la zona urbana y es de difícil acceso,

7. El proceso de restitución de tierras se hizo efectivo también hacia el pueblo huarpe, reconocido como otro grupo originario de la región. 
ya que no cuenta con un medio de transporte público que facilite la conexión con las ciudades más próximas; cuestión que urge solucionar para contar con un medio que permita trasladarse a los habitantes y visitante.

\section{Figura 1}

Localización del Pueblo Ranquel

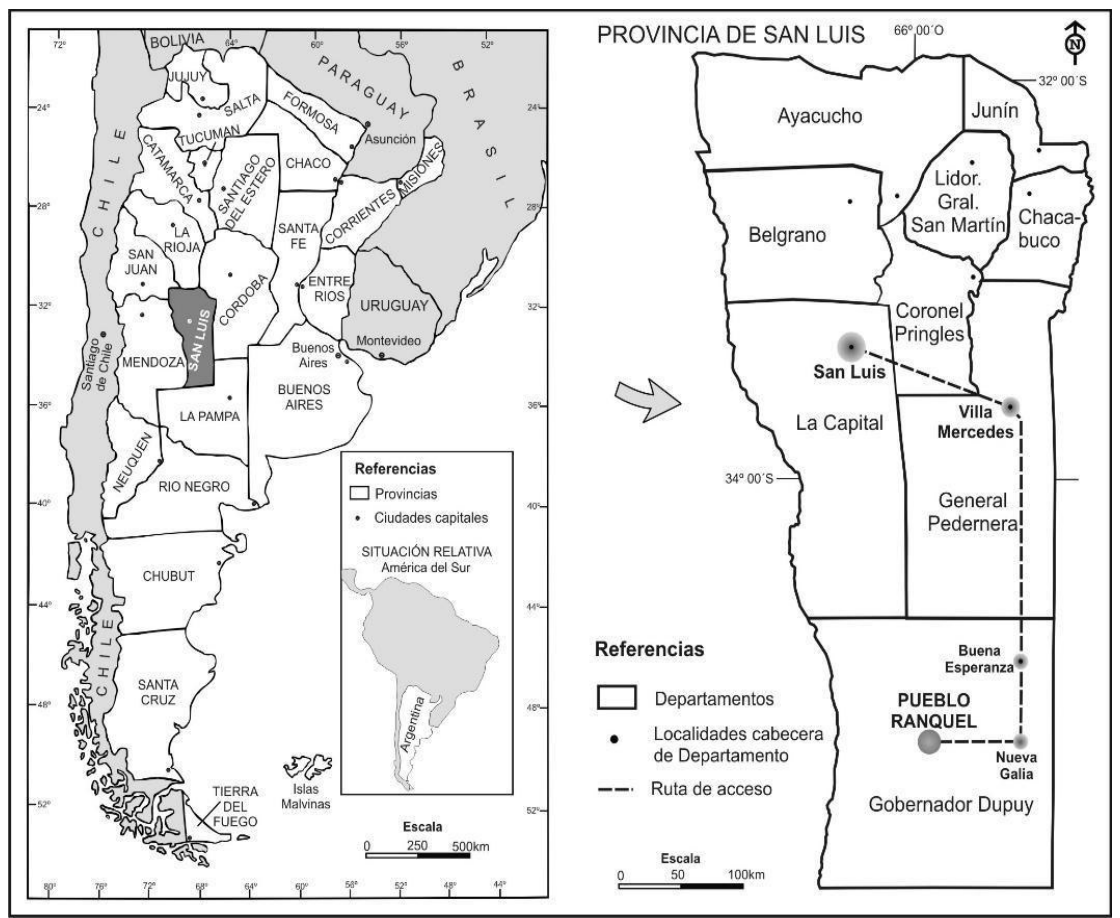

Nota. Adaptado o tomado de .....

Se caracteriza por la peculiar infraestructura de sus construcciones (24 viviendas, una escuela [Ruka Kimuy] y un hospital [Ruka Tremoi]) que reproducen el formato de los antiguos toldos indígenas ${ }^{8}$ (Figura 2), que se disponen de manera circular (Giacomasso y Curtoni, 2017). El pueblo tiene alrededor de 70 habitantes, número estimado ya que el movimiento poblacional es una constante desde su inauguración. Las familias provienen, en su mayoría, de Villa Mercedes y Justo Daract, datos a partir de una identificación previa que el Centro de Estudios Ranquelinos (CER) ${ }^{9}$ llevó a cabo considerando la existencia de rankülches en dichas ciudades; con el tiempo se fueron incorporando pobladores de localidades aledañas como Batavia y Nueva Galia.

8. Esta referencia se halla en fotografías de diversos expedicionarios a partir del siglo XIX.

9. El Centro de Estudios Ranquelinos (CER) se creó en el año 2002 con el objetivo de investigar y sistematizar estudios relacionados a los rankülches del territorio de San Luis. 


\section{Figura 2}

\section{Rukas de Pueblo Ranquel}

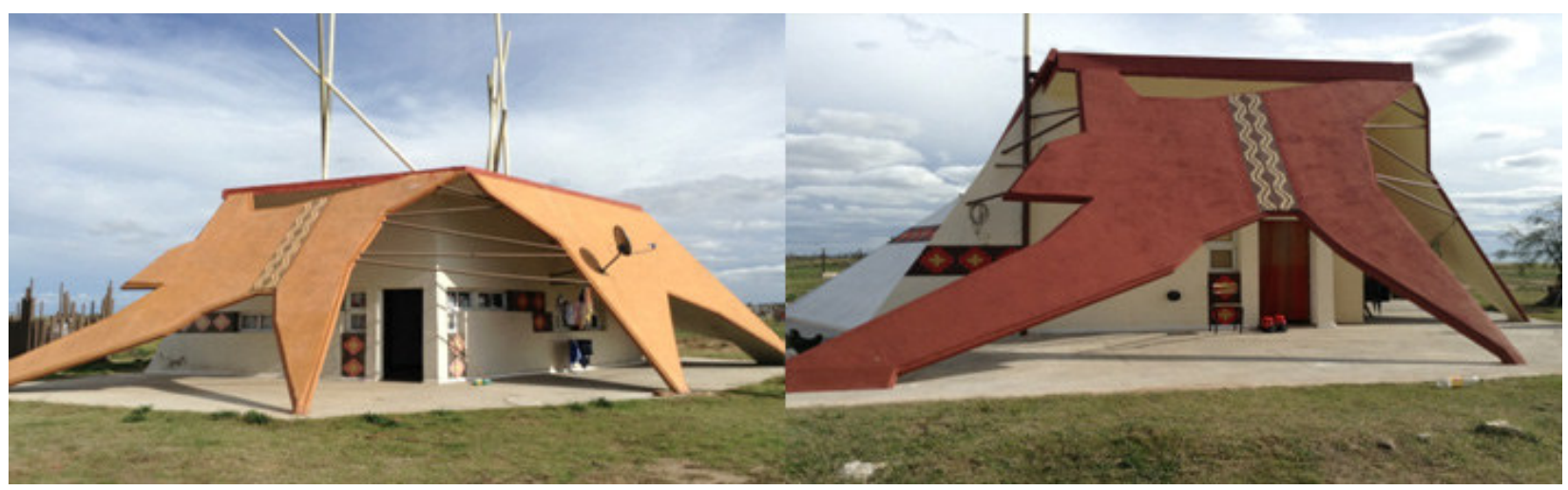

Nota. Archivo personal, 2015.

Pueblo Ranquel, dentro del extenso terreno, cuenta en su interior con tres lagunas, una en la que se pueden ver animales autóctonos, propios de la zona, tales como patos, nutrias, venados, liebres y avestruces; una segunda laguna con un anfiteatro flotante -actualmente en desuso- destinado a la realización de encuentros interculturales indígenas; y la tercera laguna, que por lo general es visitada para pescar, en los primeros años, pobladores vecinos acudían y pagaban una entrada para ingresar. A su vez, en el lugar se identificaron sitios arqueológicos, en diferentes formaciones medanosas, donde se recuperaron instrumentos y productos de talla que dan cuenta de que grupos humanos ancestrales habitaban y desarrollaban allí sus principales actividades diarias (Heider, 2016). En términos culturales, cada 23 y 24 de junio los habitantes rankülches celebran el año nuevo Rankül, donde realizan ofrendas, ceremonias y danzas propias de su cultura, las cuales pudieron relevarse mediante observaciones participantes en el lugar. En algunas oportunidades, tales bailes tradicionales son recreados para compartir prácticas indígenas con estudiantes que visitan la ruka kimuy (Casa del saber), en el marco de proyectos proyecto institucionales que tienen por objetivo promover el intercambio cultural.

Por las características mencionadas, Pueblo Ranquel se convierte en un espacio que, además de destinarse a la recreación de la etnia rankülche, tiene un potencial patrimonial y turístico desde el punto de vista tanto de la cultura que se resignifica, de sus peculiares construcciones, como de los sitios arqueológicos hallados y su entorno natural, con lagunas y animales. No obstante, su puesta en valor -a partir de proyectos vinculados principalmente con el turismo cultural- no se pudo viabilizar ni sostener en el tiempo debido a gestiones y procesos implementados sin una evaluación sustentable.

\section{Proceso de activación y actores involucrados}

El proyecto de creación de Pueblo Ranquel se encauzó fundamentalmente desde el programa Culturas 
Originarias a partir del año 2007 (Giacomasso y Curtoni, 2017), donde se constata que el gobernador Alberto Rodríguez Saá le solicitó a los miembros de dicho programa la formalización de la ley de reivindicación indígena, lo que suponía "encontrar las tierras ... con historia de ranqueles", "ofrecer el lugar" a quienes se identificaran como tales y "trasladar a dichas poblaciones" (Jefa del programa, Comunicación personal, 2013). Con respecto a ello, otros actores clave en este proceso fueron los representantes del CER que relatan sobre la convocatoria del gobierno para "obtener información sobre los habitantes ranqueles de la zona e invitarlos al pueblo", y además para "asesorar al arquitecto sobre cómo eran las viviendas de ellos [los indígenas rankülches] y construir el lugar en base a una disposición primitiva" (Comunicación personal, 2015).

Por otra parte, las actividades programadas para el desarrollo económico se basaron fundamentalmente en la producción ganadera, cuestión por la cual intervinieron agentes profesionales (agrónomos, veterinarios, contadores) que se ocuparon de dirigir y coordinar las tareas de campo y hacienda, desempeñadas por los pobladores varones. Las habitantes mujeres, por su parte, se vincularon con los trabajos de mantenimiento y limpieza de los edificios públicos y, en algunos casos, como docentes de la escuela. Para el funcionamiento de ambas instituciones también se contó con el trabajo de médicos y odontólogos, convocados por intermedio del programa de gobierno Médicos Comunitarios de San Luis, y de maestros y profesores contratados por la Universidad de La Punta.

A la intervención del Estado como proveedor de recursos humanos se suma la coparticipación otorgada a Pueblo Ranquel en carácter de Municipio transitorio (Ley V - 0677 art. 3) hasta que "obtenga un mayor estatus jurídico y se le reconozca plena autonomía y viabilidad económica” (art. 4). Mediante esta figura legal, el Poder Ejecutivo adopta las medidas conducentes a la organización del Municipio, tales como redistribuir los fondos que por coparticipación correspondan, prestar servicios y realizar obras que competan a la administración comunal y, en general, cumplir con las misiones y funciones que conciernen a las autoridades municipales, teniendo en cuenta los usos y costumbres de la Comunidad Ranquel (art. 6). Respecto de ello, la ley también establece la designación de un lonko (líder, jefe o cacique), elegido por la comunidad, "para ejecutar todas y cada una de las potestades delegadas, debiendo rendir cuenta documentada de su gestión conforme a las disposiciones de la Ley de Régimen Municipal" (art. 7). En este sentido, el lonko es quien mantiene las principales relaciones de comunicación e intercambio con el gobierno provincial.

El proceso de gestión de Pueblo Ranquel, descrito brevemente, indica una activación generada desde el gobierno y de la mano de agentes estatales que intervienen en la toma de decisiones y en las acciones respecto a la conformación del grupo de pobladores, las formas de organización económica y política y su diseño arquitectónico particular. Referente a esto, los propios habitantes afirman que fueron convocados por el Programa Culturas Originarias desde donde les informaron "del proyecto de reivindicación y sus beneficios" $\mathrm{y}$, en cuanto a las edificaciones, hicieron hincapié en que "son casitas lindas, representan a los toldos, pero antes no teníamos idea de que las iban a hacer así" (Comunicación personal, 2013), lo cual advierte sobre una planificación estatizada y no activamente participativa de los actores rankülches involucrados. 


\section{Una mirada orientada hacia el turismo}

La programación y orientación turística de Pueblo Ranquel se planteó en el mismo diseño e infraestructura. Un dato concreto de los señalado es la casa del pueblo destinada al turista, denominada La Casa del Turista -toda equipada y también con formato de ruka- y cuya construcción tuvo por objetivo que "los visitantes puedan experimentar en unos días la forma de vida de los rankülches en sus propias casitas" (Comunicación personal, 2015). Desde esta perspectiva, y tal como en la década del 90 definía la Organización Mundial del Turismo (OMT), el turismo indígena aparece con relación a las ideas de etnicidad ${ }^{10}$ como motivación de la visita.

Esta cuestión de la particularidad étnica indígena asociada al turismo ha sido objeto de argumentos especialmente críticos en cuanto a la trivialización de su patrimonio, sustentado en una idea de autenticidad y esencialidad que se vuelve atractivo para el turista como expresión de la diferencia. Precisamente el diseño del pueblo, que simula a las tolderías y aparece retirado de la zona urbana, puede leerse como la reproducción de un esquema basado en una visión "romantizada" y, por lo tanto, estereotipada de la población indígena y sus formas de vida (Ryan y Aicken, 2005). Su principal característica de aislamiento construye un modelo "exótico" para aquellos visitantes interesados en experimentar nuevas formas de entretenimiento. Desde esta perspectiva la construcción de un proyecto turístico en Pueblo Ranquel no puede entenderse disociado de un sistema reconstruido para los turistas (Grünewald, 2003) y el consumo mercantil de la cultura indígena, transfiriendo las identidades y lugares étnicos al mercado económico-turístico.

El discurso del gobernador, en los primeros meses de la fundación hacía referencia a "cómo hacer para visitar a los ranqueles ... con comidas típicas, con un museo, un vivero y por supuesto el merchandising para la venta de todas las artesanías" (Chocobare, 2013, p. 17). Los medios también promovían la visita a la comunidad para que distintos visitantes puedan "explorar la cultura en su ámbito" mediante la organización de visitas guiadas alrededor de los edificios y viviendas características, donde además "podrían participar de tareas rurales, realizar un safari fotográfico en la amplitud de su territorio de llanos, médanos y lagunas y observar la flora y fauna autóctona entre otras actividades"11. Estas publicaciones remitían al pueblo como otra oferta más de San Luis, tanto para habitantes de la provincia como para turistas de otros lugares.

Respecto de esta iniciativa el programa de cultura organizó algunas actividades que se vinculaban con dar cursos a los pobladores rankülches sobre la elaboración de platos regionales y la producción de artesanías con

10. Cabe destacar que el concepto de etnicidad aparece la mayoría de las veces relacionado con los grupos indígenas. Sin embargo, la noción de etnicidad se entiende como una construcción política de la identificación étnica o la afirmación de una identidad étnica particular -no exclusiva de lo indígena- pensada además en su carácter relacional o de interacción con otras unidades étnicas (Barth, 1976). En el caso de las poblaciones indígenas, su etnicidad particular se plantea como la pertenencia a una comunidad que es preexistente y precedente a los Estados coloniales o nacionales en el mismo territorio (Briones, 2004).

11. Nota online. Vacaciones en Pueblo Nación Ranquel.

http://admin.turismo.sanluis.gov.ar/turismoasp/paginas/pagina.asp?PaginaID=493 
materias primas de la zona ${ }^{12}$. Este proyecto, sin embargo, nunca llegó a implementarse, aunque en los primeros meses de fundación los pobladores recibieron visitas en las que mostraron el pueblo y las características de sus modos de vida, pero de manera espontánea sin una acción programada. Por su parte, existieron algunos talleres de técnicas artesanales que se dictaron por una machi pampeana (guía espiritual) que fue invitada por el gobierno de San Luis para colaborar con la enseñanza de la producción artesanal y las danzas tradicionales, pero que se sostuvieron solo por unos meses hasta que la machi se mudó del lugar. Por todo lo anterior, el turismo que se difundía consistió fundamentalmente en planes gubernamentales que no alcanzaron a desarrollarse por falta de una apropiación de sus habitantes.

Una posición crítica al respecto suele caracterizar estas áreas de destino -como la de Pueblo Ranquel- como una forma de subordinación neocolonial o neoimperialista de minorías étnicas. No obstante, aún sin dejar de reconocer esta situación en varias ocasiones, muchos estudios plantean las potencialidades del turismo para los pueblos indígenas (Guerreiro, 2007) en tanto puede contribuir a la reactivación de prácticas y sentidos identitarios y al afianzamiento económico y territorial de la población para su desarrollo sustentable.

Con respecto a lo anterior algunas experiencias demuestran que la actividad turística no siempre implica adaptarse a la lógica del mercado, sino que adquiere singularidades propias en función de particularidades locales. Por ello, resulta fundamental la consideración de las visiones, intereses y expectativas de las poblaciones a la hora de desarrollar programas turísticos, en tanto que son parte consustancial e indisociable de la conformación de dichos programas, contribuyendo tanto al éxito como al fracaso de los mismos. Esta importancia, dada a la participación de las comunidades, se considera un derecho humano que Argentina ratifica por medio del Convenio 169 de la Organización Internacional del Trabajo (OIT), la Declaración de la ONU del año 2007 y la Declaración de la Organización de las Estados Americanos (OEA) del año 2016, estas últimas referidas específicamente a los derechos de los pueblos indígenas a determinar libremente su desarrollo económico, político y social.

En relación particular con el turismo, la Carta del Consejo Internacional de Monumentos y Sitios (ICOMOS, 1999) hace explícito el deber de involucrar a las comunidades; y en lo referente a la sustentabilidad el documento de la Organización de las Naciones Unidas para la Educación, la Ciencia y la Cultura enfatiza en el reconocimiento de los intereses de la población local, puesto que los mismos condicionan la sostenibilidad y los resultados de una gestión sustentable (UNESCO, 2012 y 2014a). En este sentido, si bien la participación forma parte de los objetivos a cumplir en varios documentos, normas y declaratorias, el caso que aquí se presenta demuestra que los intereses de los diversos actores involucrados no fueron incluidos de forma directa. Sin embargo, varios pobladores manifiestan el deseo de generar proyectos relacionados con el turismo, lo

12. Nota online. San Luis Proyecto de Desarrollo para la Comunidad Ranquel.

http://www.hostnews.com.ar/despachos/4/p1104072011.htm 
cual expresa la necesidad de rever las gestiones realizadas hasta el momento, teniendo en cuenta el interés de la comunidad. En este sentido, Foladori (2002) señala que la participación es la temática más interesante en la discusión sobre sustentabilidad sociocultural, constituyendo un indicador de libertades democráticas, de equidad en las decisiones, y también un elemento decisivo en la potenciación de esfuerzos productivos.

\section{Lineamientos para una gestión sustentable}

A partir del análisis previo este estudio presenta como resultado el desarrollo de lineamientos metodológicos que incluyen estrategias para la gestión de Pueblo Ranquel, pero aplicables también a la gestión del patrimonio cultural regional. Estos lineamientos incluyen una serie de pasos y estrategias operativas construidas sobre la base de conocimientos teóricos en el tema y, principalmente, de información recabada del pueblo durante la investigación cualitativa. Los mismos se basan, a su vez, en una perspectiva de la sustentabilidad sociocultural, la cual reconoce dimensiones claves en el proceso de gestión como la inclusión y participación comunitaria (Greenwood, 2000; Caraballo, 2012; Castillo, 2015).

Cabe destacar que esta propuesta tiene la intención de orientar a gestores del patrimonio y/o agentes de gobierno del área de cultura que pretenden desarrollar un nuevo proyecto de gestión, partiendo de un esquema metodológico efectuado de acuerdo a necesidades e intereses relevados en el proceso de trabajo en el área. En la Figura 3 se describe la planificación y evaluación de acciones a desarrollar.

\section{Figura 3}

Esquema para la gestión sustentable

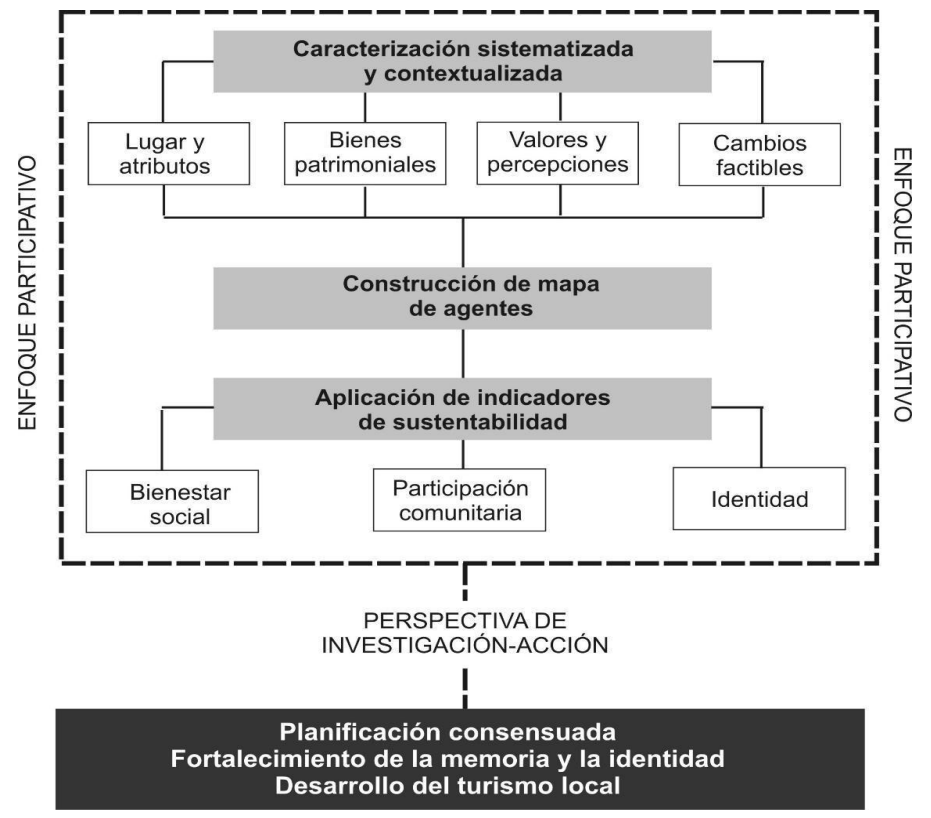

Nota. Elaboración propia. 
Por empezar, el primer aspecto a considerar para una activación y revaloración cultural del sitio, que además involucre proyectos turísticos, es desarrollar una caracterización del área que incluya datos sistematizados y contextualizados que permitan comprenderla y valorarla mejor (Grenville y Fairclough, 2004-2005). En ese marco, resulta necesario poner en marcha un proceso que involucre una serie de pasos que se describen a continuación: (a) la definición del lugar y de sus atributos; (b) la determinación de los bienes patrimoniales o potenciales de serlo; (c) la identificación de valores y percepciones de la comunidad; y (d) el análisis de factibles cambios a partir del uso de dicha área o espacio. Toda esa información producida y actualizada es esencial para la consecución de cualquier proyecto adecuado a las particularidades de la comunidad o la región, ya que permite determinar sus características y necesidades. Por otra parte, la construcción de un mapa de agentes, donde se identifiquen -mediante un listado o red- los actores clave y sus relaciones resulta crucial para acceder a las percepciones, significaciones, valores, conocimientos y/o usos relacionados a los lugares, además de sus intereses y expectativas concretas en torno al desarrollo de actividades sustentables en el área. Para ello las tareas específicas dentro de esta etapa requerirán de la realización de entrevistas abiertas y en profundidad, conversaciones personales informales y también el uso de encuestas que puedan aportar información cuantitativa que complemente la cualitativa extraída de las entrevistas.

Al mismo tiempo, metodológicamente, otro instrumento que puede contribuir a reflejar las preocupaciones y los temas de interés, es la selección y aplicación de indicadores (Rueda, 1999) que -según variables que pueden ser territoriales, administrativas, sociales- sirvan para evaluar problemas y oportunidades que los actores y las instituciones identifiquen como prioritarios para la sustentabilidad del lugar (UNESCO, 2014b). Desde el punto de vista metodológico, la evaluación de la sustentabilidad mediante indicadores se ha convertido en una tarea clave de los gobiernos para alcanzar objetivos comunes desde un enfoque integral. Este tipo de evaluación permite obtener un diagnóstico interesante para monitorear los progresos contribuyendo a la toma de decisiones. Los beneficios de la evaluación son múltiples dado que apoyan el proceso de planificación y de formulación de políticas de mediano y largo plazo, permiten detectar procesos o áreas en las cuales existen problemas de gestión, facilitan la realización de ajustes en los procesos internos, readecuando cursos de acción, entre otros. Por otra parte, permiten establecer mayores niveles de transparencia. Existen algunos antecedentes de construcción de indicadores vinculados con áreas o sitios de interés patrimonial que aportan bases relevantes para la evaluación de la sustentabilidad, especialmente en su dimensión sociocultural, tendientes a contribuir a la toma de decisiones (Álvarez y Zulaica, 2015; Endere y Zulaica, 2015; Sánchez y Zulaica, 2018).

En el caso de Pueblo Ranquel, y de acuerdo a lo recabado en el campo y los antecedentes analizados, el diseño de indicadores podría incluir tres ejes conectados vinculados, a continuación: (1) el bienestar social de la población, (2) la participación comunitaria en la gestión sobre su territorio, y (3) la identidad. En relación con los mismos, podría relevarse información sobre la condición de bienestar de los habitantes, el grado de participación en acciones de interés común al interior del pueblo y los aspectos que reconocen como primordiales de su identidad lo que contribuiría a evaluar debilidades y oportunidades que permitan proyectar 
acciones participativas a implementar, entre ellas las vinculadas al turismo. En este sentido, la organización de mesas de diálogo con los diferentes grupos de interés involucrados también resultaría clave para acordar líneas de acción a partir de una indagación previa.

La construcción de estos instrumentos metodológicos para repensar en las políticas de gestión, permitirá no funcionar como un manual de procedimientos, sino como orientaciones y perspectivas de investigaciónacción que, además, requieran ajustarse al contexto donde se implementen. Este conjunto de estrategias vuelve a su vez visible la complejidad del desarrollo de programas de sustentabilidad regional en San Luis, que incluye la planificación consensuada de acciones, en este caso desde una mirada del patrimonio cultural y su potencialidad para el bienestar social, el fortalecimiento de la memoria y la identidad, así como también para el desarrollo del turismo local.

La incorporación de estrategias de gestión participativa en el desarrollo del turismo local, permitirá evaluar alternativas y facilitar acuerdos interinstitucionales con la comunidad. La construcción colectiva del proceso de gestión y la cooperación son las llaves para garantizar la sustentabilidad del desarrollo del turismo. El turismo, desde esta perspectiva participativa, puede suscitar consecuencias dinamizadoras como visibilizar a la población, la activación de prácticas tradicionales que potencien referentes identitarios (Morales, 2006); también, puede contribuir a reconstruir, producir y mantener la cultura de un pueblo o comunidad (Santana, 2003). En este sentido, y de acuerdo con el interés de pobladores rankülches de revitalizar aspectos culturales a partir del turismo, resulta interesante realizar evaluaciones sobre una potencial gestión sustentable que contribuya al desarrollo de la comunidad y al bienestar local.

\section{Conclusiones}

En la provincia de San Luis, los proyectos denominados de desarrollo sustentable implementados por el gobierno provincial incluyen el tema de la cultura considerándolo un factor decisivo para incrementar el capital social y para alcanzar la sostenibilidad desde una perspectiva centrada en el ser humano. Entre dichos proyectos la inclusión de los pueblos indígenas, materializados en la restitución de tierras y en la construcción de obras como forma de recuperar y revitalizar la raíz y memoria puntana, evidencian un interés político por la identidad y diversidad cultural provincial, vinculado además a la puesta en valor del patrimonio cultural y al desarrollo de emprendimientos socioproductivos y turísticos. Ello, ha sido un objetivo explícito del gobierno de San Luis con vistas a coordinar acciones conjuntas para su crecimiento.

No obstante, y en el caso que se presenta en este estudio, se observa que las gestiones que activaron el área distaron de una evaluación preliminar de las condiciones políticas, económicas y sociales que la atraviesan y no relevaron e identificaron las valoraciones y significados de los grupos que la habitan. Proyectos como el de turismo -planificados antes de la edificación y fundación del pueblo- son ejemplo de estas activaciones realizadas desde el Estado que no lograron concretarse por falta de identificación de sus habitantes quienes no participaron directamente -como voz involucrada- en el armado de dichos planes. 
$\mathrm{Al}$ respecto, una cuestión crucial, teniendo en cuenta las representaciones, expresiones y usos acerca del patrimonio, es la necesidad de incluir la perspectiva de los actores locales en los procesos de elaboración de las políticas de manejo de los recursos culturales con el fin de implementar una gestión participativa e inclusiva y potencialmente sustentable. Sin duda la participación es un concepto central en toda gestión ya que habilita a la interacción de individuos y grupos en las diferentes etapas en las cuales se resuelven los asuntos de interés. Caso contrario, las propuestas diseñadas no prosperan, en la medida en que no involucran los deseos, objetivos e intereses de los habitantes, aun cuando sean promovidas desde el poder oficial.

En este punto, cabe destacar una nota reciente (Agencia San Luis 05/2018) ) $^{13}$, en la que se hace referencia a la visita del ministro de turismo a Pueblo Ranquel, con el objetivo de presentar el equipo de trabajo que está a cargo de pueblos originarios, "para que estén en contacto permanente con ellos y coordinar acciones en el futuro inmediato de los ranqueles, así lograr una sustentabilidad económica acorde al reconocimiento que tienen en la provincia". En dicha publicación el ministro también destaca:

Nos hemos puesto a disposición de los lonkos y la comunidad ranquel para ayudarlos en todo lo que esté a nuestro alcance porque es nuestro deber colaborar con esta comunidad y lograr las mejores condiciones para los que la habitan.

De esta manera, se advierte un reconocimiento de parte del Estado provincial de sus obligaciones y una preocupación por construir acciones colectivas entre funcionarios de gobierno y demandas locales.

A raíz de este caso se ofrecen una serie de recomendaciones metodológicas para la gestión sustentable donde se promueve el enfoque participativo, sobre todo en el sector del patrimonio, dada la percepción del patrimonio como bien compartido de las comunidades y factor que garantiza la sostenibilidad de estas. Desde esta perspectiva se reconoce que los niveles de participación cultural están sólidamente vinculados al desarrollo, ya que son un reflejo del capital social de una comunidad y del sentimiento de integración y bienestar de sus miembros y, además, fomenta la generación de relaciones sociales de respeto mutuo e inclusión. Por ello, los proyectos y programas encauzados por la provincia orientados a cumplir con la Agenda 2030 de Desarrollo Sostenible, merecen una planificación, evaluación y revisión continua de acciones a la medida de las necesidades de los grupos sociales que involucra.

En este contexto, el reto principal consiste en consolidar nuevas estrategias de gestión del patrimonio cultural basadas en principios reales de sustentabilidad. Este desafío inspira a seguir profundizando en investigaciones, cuyos resultados permitan avanzar hacia la sustentabilidad del desarrollo del turismo, incluyendo la participación en la agenda política.

13. Nota online. Visita al Pueblo Nación Ranquel.

http://agenciasanluis.com/notas/2018/05/15/visita-al-pueblo-nacion-ranquel 


\section{Agradecimientos}

Agradecemos al pueblo rankülche en general y a los integrantes de Pueblo Ranquel de San Luis en particular, por su participación y apoyo para realizar la investigación. Este trabajo fue financiado con fondos provenientes de la Agencia Nacional de Promoción Científica y Tecnológica de Argentina, por medio del PICT-0290, Investigaciones Arqueológicas en Sierras y Llanuras del Área Centro-Este de la Provincia de San Luis, dirigido por el Dr. Rafael Pedro Curtoni, y el PICT0551/16, Investigación, Gestión y Significación Social del Patrimonio Cultural en el Centro de Buenos Aires y Centro-Este de San Luis, dirigido por la Dra. María Luz Endere.

\section{Conflicto de intereses}

Los autores no tienen conflicto de intereses con el contenido de este trabajo.

\section{Contribución de autoría}

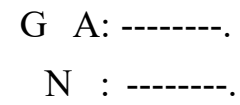

\section{Referencias}

Achkar, M. (2005). Indicadores de Sustentabilidad. En M. Achkar (Ed.), Ordenamiento Ambiental del Territorio (pp. 1-13). Montevideo, Uruguay. Udelar.

Álvarez, S. y Zulaica, L. (2015). Indicadores de sustentabilidad en sistemas de albarradas: aportes metodológicos. Revista Letras Verdes, 18, 184-207.

Barth, F. (1976). Los grupos étnicos y sus fronteras. Fondo de Cultura Económica.

Bonfil, G. (2004). Pensar nuestra cultura. Nuestro patrimonio cultural: un laberinto de significados. Diálogos en la acción 1, 117-134.

Briones, C. (2004). Construcciones de Aboriginalidad en Argentina. Société Suisse des Américanistes 68, 73-90.

Caraballo, C. (2012). El patrimonio cultural y la gestión participativa: ejercicio incompleto de los derechos de la ciudadanía. Defensor. Revista de Derechos Humanos 6, 19-25.

Castillo, A. (Ed.). (2015). Actas del Segundo Congreso Internacional de Buenas Prácticas en Patrimonio Mundial: Personas y comunidades. Universidad Complutense de Madrid, Madrid, España.

Chocobare, M. (2013). Ranqueles vivir al sur: acciones gubernamentales en el proceso de conformación de una "comunidad ranquel" en San Luis a comienzos del siglo XXI. Revista Tefros 11, 1-23.

Chocobare, M. (2016). Celebrar la puntanidad. Políticas gubernamentales y usos del pasado, una aproximación desde la crítica poscolonial [Segundo Seminario Taller TEFROS]. UNRC, Córdoba, Argentina.

Elizalde, A. (2003). Sustentabilidad: ¿para todos o sólo para algunos? Polis 5. https://journals.openedition.org/polis/6856.

Endere, M. L. y Zulaica, L. (2015). Sustentabilidad socio-cultural y Buen Vivir en sitios patrimoniales: evaluación del caso Agua Blanca, Ecuador. Ambiente \& Sociedade, 18(4), 265-290.

Fernández, R., Allen, A., Burmester, M., Malvarez, M., Navarro, L., Olszewski, A. y Sagua, M. (1999). Territorio, Sociedad y Desarrollo Sustentable, Estudios de Sustentabilidad Ambiental Urbana. Centro de Investigaciones Ambientales, FAUD, UNMDP. 
Foladori, G. (2002). Avances y límites de la sustentabilidad social. Economía, Sociedad y Territorio, 3(12), 621-637.

Gallopin, G. (2003). Sostenibilidad y Desarrollo Sostenible: un enfoque sistémico. CEPAL, Serie Medio Ambiente, División de Desarrollo Sostenible y Asentamientos Humanos.

García, N. (1999). Los usos sociales del patrimonio cultural. En E. Aguilar (Comp.), Patrimonio etnológico. Nuevas perspectivas de estudio (pp. 16-33). Consejería de la Cultura, Sevilla, España.

García, D. y G. Priotto. (2008). Módulo 2: La sustentabilidad como discurso ideológico. Programa de Estrategia Nacional de Educación Ambiental, SAySD.

Gez, J. (1996). Historia de la provincia de San Luis. Gobierno de la provincia de San Luis.

Giacomasso, M. V. (2016). Patrimonio, discursividades y políticas culturales indígenas: un análisis en Pueblo Ranquel, San Luis, Argentina [Tesis doctoral, Universidad Nacional de Quilmes]. Bernal. https://ridaa.unq.edu.ar/handle/20.500.11807/216?show=full

Giacomasso, M. V y R. Curtoni (2017). Patrimonio y paisaje cultural rankülche. La relación pasado-presente en la construcción de "Pueblo Ranquel" (San Luis, Argentina). Revista Intersecciones en Antropología 18, 233-244.

Grenville, J. y Fairclough, G. (2004). Characterisation. Introduction. Conservation Bulletin 47, 2-3.

Greenwood, D. (2000). De la observación a la investigación-acción participativa: una visión crítica de las prácticas antropológicas. Revista de Antropología Social 9, 27-49.

Grünewald, R. (2003). Turismo e etnicidade. Horizontes Antropológicos 20, 141-159.

Guber, R. (2011). La etnografía. Método, campo y reflexividad. Siglo XXI.

Guerreiro, E. (2007). O turismo comunitario como agente de desenvolvimento social e a comunidade guarani nas Ruinas Jesuíticas de São Miguel das Missões. Pasos. Revista de Turismo y Patrimônio Cultural 3, 343-352.

Guimarães, R. (2003). Tierra de sombras: Desafíos de la sustentabilidad y del desarrollo territorial y local ante la globalización corporativa. Medio Ambiente, División de Desarrollo Sostenible y Asentamientos Humanos 67, 1-59.

Heider, G. (2016). Los pueblos originarios en el norte de Pampa Seca. Relaciones de la Sociedad Argentina de Antropología 41(2), 375-396

ICOMOS (1999). Carta Internacional sobre turismo Cultural. La gestión del patrimonio en los sitios con patrimonio significativo. http://www.icomos.org/charters/tourism_sp.pdf.

Iglesias, A. y Martínez, A. (2007). El Desarrollo Sostenible: Una ecuación para construir conocimiento. DELOS: Desarrollo Local Sostenible 1. www.eumed.net/rev/delos/00/.

Lobo, C. (2015). La 'irrupción’ de las culturas originarias en el discurso político del siglo XXI en la provincia de San Luis [Actas del VIII Seminario del Cono Sur. Políticas, actores y prácticas de comunicación. Asociación Latinoamericana de Investigación en Comunicación (ALAIC). https://www.alaic.org/site/viii-seminario-cordoba-argentina-2015/

Morales, H. (2006). Turismo comunitario: una nueva alternativa de desarrollo indígena. Revista de Antropología Iberoamericana, 1(2), 249-264.

Prats, L. (2005). Concepto y gestión del patrimonio local. Cuadernos de Antropología Social 21, 17-35.

Prats, L. (2007). Antropología y Patrimonio. Editorial Ariel.

Rosas, A. (2005). Las disputas por el patrimonio. Transformaciones analíticas y contextuales de la problemática patrimonial en México. En N. García (Comp.), La antropología urbana en México (pp. 60-95). UAM.

Rueda, S. (1999). Modelos e indicadores para ciudades más sostenibles. Fundación Fórum Ambiental.

Ryan, C. y Aicken, M. (Comps.). (2005). Indigenous Tourism: The Commodification and Management of Culture. Elsevier.

Sánchez, L. y Zulaica, L. (2018). Ciudades vivas: aportes mediante indicadores de sustentabilidad patrimonial residencial en aglomeraciones intermedias bonaerenses argentinas. Casos Mar del Plata y Tandil. Dearq, 23(2), 178-187.

Santana, A. (2003). Turismo cultural, culturas turísticas. Horizontes Antropológicos 20, 31-56. 
UNESCO. (2012). Manual de investigación cultural comunitaria. UNESCO

UNESCO. (2014a). Gestión del Patrimonio Mundial Cultural. UNESCO.

UNESCO. (2014b). Indicadores UNESCO de cultura para el desarrollo. UNESCO.

Van Maanen, J. (1995). Representation in Ethnography. Sage.

María Vanesa Giacomasso

Doctora en Ciencias Sociales y Humanas (UNQ), licenciada en Comunicación Social (UNICEN). Desde 2020 investigadora del Consejo Nacional de Investigaciones Científicas y Técnicas (CONICET). Docente auxiliar de la Facultad de Ciencias Sociales (UNICEN). Participa en proyectos de investigación interdisciplinarios desde 2012 en el Instituto INCUAPA y en redes de carácter internacional (Red Trama 3 CYTED y ReCA PCI LAC).

vanegiac005@gmail.com

ORCID: http://orcid.org/0000-0003-1754-877X

Laura Zulaica

Doctora en Geografía (UNS), magister y especialista en Gestión Ambiental (FICES-UNSL), licenciada en Diagnóstico y Gestión Ambiental (FCH-UNCPBA). Desde 2012 investigadora del Consejo Nacional de Investigaciones Científicas y Técnicas (CONICET). Profesora adjunta en la Facultad de Humanidades (UNMDP). Participa de proyectos de investigación en la UNCPBA, UNS y UNMDP desde 1999.

laurazulaica@yahoo.com.ar

ORCID: https://orcid.org/0000-0001-8101-5957 